\title{
RISK FACTORS OF HAND, FOOT AND MOUTH DISEASE (HFMD) OUTBREAK CASES AMONG CHILDREN UNDER FIVE YEARS OLD IN A NORTH EASTERN STATE OF PENINSULAR MALAYSIA
}

\author{
Nur Akmal Ismail ${ }^{1}$, Wan Mohd Zahiruddin ${ }^{1}$ and Nik Mohd Hafiz Mohd Fuzi ${ }^{2}$ \\ ${ }^{1}$ Department of Community Medicine, School of Medical Sciences, Universiti Sains Malaysia, 16150 Kubang Kerian, \\ Kelantan, Malaysia \\ ${ }^{2}$ Communicable Disease Section, Kelantan State Health Department, 15590 Kota Bharu, Kelantan, Malaysia
}

Corresponding author: Wan Mohd Zahiruddin Wan Mohammad

Email: drzahir@usm.my

\begin{abstract}
Hand, foot and mouth disease (HFMD) outbreak is a contagious illness and typically occur in the children of less than five years old. The was a marked rise in the number of HFMD outbreak cases was observed in Kelantan, a north-eastern State of Malaysia in 2018. This study aimed to determine risk factors for HFMD outbreak cases to inform potential strategies for prevention and control to reduce the occurrence of outbreak in the population. The data of HFMD cases was collected from Communicable Disease Control Information System (CDCIS) e-Notifikasi, managed by the Disease Control Division, Ministry of Health Malaysia for 2018. Totally, 1026 HFMD data cases were retrieved in the descriptive study. Of the total cases, a comparative cross-sectional analysis was performed on 70 HFMD outbreak cases and 198 non-outbreak cases using simple random sampling. Multiple logistic regression test was done to identify factors associated with HFMD outbreak cases among the children aged under five years old. Home-care (aOR 0.008; 95\% Cl: $0.001,0.067, p$-value $<0.001)$, attendance to the kindergarten (aOR 0.330; $95 \% \mathrm{Cl}: 0.114,0.957, p$-value $=0.041)$ and warm season (aOR 0.154; 95\% Cl: 0.043, 0.557, $p$-value=0.004) were found to have a significant association to lower the risk for HFMD outbreak cases in the study. This study was able to identify few significant factors associated with the HFMD outbreak which should be considered by the stakeholders. Further research to evaluate the epidemiology of the HFMD outbreak in Malaysia are needed.
\end{abstract}

Keywords: Hand, foot and mouth disease, outbreak, factors

\section{INTRODUCTION}

Hand, foot and mouth disease (HFMD) is a viral illness that has clinical manifestations of ulceration of oral mucosa and vesicular rashes appear at the palms, feet and sometimes at the buttocks. Infants and children younger than five years old are commonly susceptible group to get HFMD. Recently, HFMD has gained new challenge because of the clinical, epidemiological, and etiological features of this disease may be significantly different from those believed initially especially during the occurrence of epidemics ${ }^{1}$. HFMD outbreaks had occurred in many parts of the world, including the United States of America, Australia, Europe, Brazil, Japan, and Malaysia $^{2}, 3$. The increasing number of HFMD outbreaks worldwide had brought HFMD to international attention due to complications caused by death.

First Malaysia HFMD outbreak occurred in East Malaysia in 1997 before it was spread to the Peninsular Malaysia with recorded 4253 cases with 41 deaths $^{4}$. In 2000, Malaysia was again troubled by a deadly HFMD epidemic then followed by three yearly large outbreaks in 2003, 2006 and 2009 in the East Malaysia ${ }^{5}$. Data from Ministry of Health Malaysia in 2018 reported 76,446 HFMD cases outbreaks nationwide significantly differ from 2017 which was 29,358 cases. It was clearly shown that there was $160 \%$ increment in a total of HFMD cases from 2017 to 2018.

HFMD can affect all age groups, however, age of less than 5 years old had been established to have an association with the increase risk of HFMD infection. About more than 70\% of HFMD outbreak cases were among the children aged less than five years old ${ }^{4,6}$. Majority of HFMD infection affected male children than female children ${ }^{7-9}$. Male children are easily making friends with others at their age and become more physically contacted to each other. HFMD was commonly seen among the rural residents ${ }^{10}, 11$. This has been associated with the inadequate knowledge and practices on HFMD led to delayed care and poor sanitation. The kindergarten and nursery were both susceptible to the transmission of HFMD among children due to constant close interaction with each other as they stay and play in the same areas ${ }^{8}$. Seasonal factor is an important risk that associated with the increasing of HFMD outbreak cases. They were occurred mostly during rainy season and also in winter ${ }^{12,}{ }^{13}$. Immunity system of children can degrade during rainy season, rendering them vulnerable for HFMD infection ${ }^{12}$.

Surveillance data in Kelantan showed that the total confirmed outbreak cases were increased from 20 cases in 2017 to 61 in 2018, with only two outbreaks involving five cases registered ${ }^{14}$. HFMD 
outbreak cases were increasing from the past five years in Kelantan and the infection is one of Kelantan's five most recorded outbreaks in $2018^{15}$. This increment demonstrates that there are many common risk factors related with HFMD outbreak cases in the population. Therefore, a study is required to determine the risk factors influencing the HFMD outbreak cases in this region. The findings will be beneficial to the database of HFMD, especially for stakeholders such as Disease Control Division in $\mathrm{MOH}$ Malaysia in prevention and control of the HFMD outbreak.

\section{METHODS}

\section{Study design and setting}

A comparative cross-sectional study was conducted between December 2019 and April 2020 among notified HFMD outbreak cases and non-outbreak cases in 2018 of Kelantan State. Kelantan is a northeastern state of Peninsular Malaysia with the area of about $15,000 \mathrm{~km} 2$ comprising of 10 districts. There are two annual seasons which are the Southwest monsoon season which occur from May to August that brings the warm season in the state and Northeast monsoon season which happens from November to February that brings the rainy season to this region ${ }^{16}$.

\section{Participant recruitment and data collection}

This study involved secondary data collected from Communicable Disease Control Information System (CDCIS) e-Notifikasi, managed by the Disease Control Division, Ministry of Health Malaysia. The inclusion criteria were all HFMD cases which had been notified via CDCIS eNotifikasi to Department of Communicable Disease Control (CDC) Kelantan in 2018 and the exclusion criteria was any incomplete data in CDCIS e-Notifikasi more than $20 \%$ missing data which cannot be verified further. The studied variables include the sociodemographic variable such as age, gender, race, residence and institution; clinical variable like hospital admission and environmental variable such as seasonal factor. In descriptive study, all cases that fulfilled criteria which is 1026 HFMD cases were included in the study. Meanwhile, in the comparative cross-sectional study, sample size estimation was done using two proportion formula with alpha value of 0.05 , power of $80 \%$ and $1: 2$ ratio which yielded 94 for HFMD outbreak cases and 198 for HFMD non-outbreak. Simple random sampling procedure was done from the respective pools of cases. However, for outbreak cases, the sample was lesser, which was 70 cases than the calculated sample size; therefore, all were included. The outcome was based on outbreak occurrence which can be categorized into outbreak cases and non-outbreak cases.

\section{Case definitions}

According to the Case Definitions of Infectious Diseases in Malaysia $3^{\text {rd }}$ Edition, HFMD cases were defined as clinical case definition and laboratory criteria for diagnosis. Clinical case definition of HFMD is any child of 10 -year-old and below with mouth or tongue ulcer; maculopapular rashes and /or vesicles on palms and soles and with or without history of fever. Laboratory criteria for diagnosis is any case that has clinical symptom and positive for virus Coxsackieviruses (CV) A16, A5, A9, A10, B2, B5; and Enterovirus 71 and other enteroviruses which could cause HFMD, isolated or detected from stool or vesicle fluid or mouth ulcer or saliva. The HFMD outbreak is defined as the occurrence of two or more cases in the same locality within the incubation period of 6 days ${ }^{17}$.

\section{Statistical analysis}

Descriptive statistics were used to describe the general characteristics of the HFMD cases. The association between categorical variables and the HFMD outbreak occurrence was using the regression and presented as odds ratio (OR) and 95\% Confident Interval $(\mathrm{Cl})$. P-value of less than 0.25 from the simple logistic regression or clinical importance variables were selected for multiple logistic regression. In the final model, the level of significance was set at $p$-value of less than 0.05 . All the data were analyzed using the SPSS software Ver. 24.

\section{RESULTS}

From the overall 1026 HFMD cases in Kelantan which fulfilled study criteria, 70 of them were from HFMD outbreak cases, equivalent to $6.8 \%$ and 956 (93.2\%) were HFMD non-outbreak cases. The characteristics of HFMD cases is shown in Table 1.

A total of 268 HFMD cases were included in the univariate analysis after the sampling method was applied. As shown in Table 2, there were significant associations between HFMD outbreak cases and age group, institution, season and admission status. However, all the significant and clinically important variables were included in the multiple logistic regression.

The preliminary main effect model consists of three variables, which were the age group, institution, and season. A significant interaction was found in between age and season; therefore, the effect of season depends on the age group. Analysis of simple effects study was conducted by looking results for the subgroups separately by splitting the age group in-between age less than 5 years and 5 years and above. At this point, there were 146 cases under the subgroup of age less than 5 years, consisting of 61 outbreak cases and 85 non-outbreak cases. Meanwhile, under the subgroup age of 5 years and above, there were 122 cases consisting of nine outbreak cases and 113 non-outbreak cases. 
Table 1: Descriptive study on characteristics of HFMD cases by outbreak status in Kelantan in 2018 $(n=1026)$

\begin{tabular}{|c|c|}
\hline Variables & $\begin{array}{c}\text { Total of HFMD cases } \\
n(\%)\end{array}$ \\
\hline \multicolumn{2}{|l|}{ Age (years) } \\
\hline $\begin{array}{l}5 \text { and more } \\
\text { Less } 5\end{array}$ & $\begin{array}{l}545(53.1) \\
481(46.9)\end{array}$ \\
\hline \multicolumn{2}{|l|}{ Race } \\
\hline $\begin{array}{l}\text { Non-Malay } \\
\text { Malay }\end{array}$ & $\begin{array}{c}37(3.6) \\
989(96.4)\end{array}$ \\
\hline \multicolumn{2}{|l|}{ Gender } \\
\hline $\begin{array}{l}\text { Female } \\
\text { Male }\end{array}$ & $\begin{array}{l}454(44.2) \\
572(55.8)\end{array}$ \\
\hline \multicolumn{2}{|l|}{ Residence } \\
\hline $\begin{array}{l}\text { Rural } \\
\text { Urban }\end{array}$ & $\begin{array}{l}806(78.6) \\
220(21.4)\end{array}$ \\
\hline \multicolumn{2}{|l|}{ Institution } \\
\hline $\begin{array}{l}\text { Nursery } \\
\text { Kindergarten } \\
\text { School } \\
\text { Others }\end{array}$ & $\begin{array}{l}168(16.4) \\
393(38.3) \\
187(18.2) \\
278(27.1)\end{array}$ \\
\hline \multicolumn{2}{|l|}{ Season } \\
\hline $\begin{array}{l}\text { Rainy } \\
\text { Less rainy } \\
\text { Warm }\end{array}$ & $\begin{array}{l}213(20.8) \\
393(38.3) \\
420(40.9)\end{array}$ \\
\hline $\begin{array}{c}\text { Hospitalization } \\
\text { No } \\
\text { Yes }\end{array}$ & $\begin{array}{c}979(95.4) \\
47(4.6)\end{array}$ \\
\hline
\end{tabular}

Table 2: Simple logistic regression of factors associated with HFMD outbreak $(n=268)$

\begin{tabular}{|c|c|c|c|}
\hline Variable & Crude OR $(95 \% \mathrm{Cl})$ & Wald Statistics (df) & $p$-value \\
\hline \multicolumn{4}{|l|}{ Age (years) } \\
\hline 5 and more & 1 & & \\
\hline Less 5 & $9.010(4.238,19.158)$ & 32.629 (1) & $<0.001$ \\
\hline \multicolumn{4}{|l|}{ Residence } \\
\hline Rural & 1 & & \\
\hline Urban & $0.926(0.485,1.766)$ & $0.055(1)$ & 0.815 \\
\hline \multicolumn{4}{|l|}{ Institution } \\
\hline Nursery & 1 & & \\
\hline Kindergarten & $0.99(0.048,0.205)$ & $39.221(1)$ & $<0.001$ \\
\hline School & $0.010(0.001,0.081)$ & $18.968(1)$ & $<0.001$ \\
\hline Others & $0.007(0.001,0.052)$ & $23.067(1)$ & $<0.001$ \\
\hline \multicolumn{4}{|l|}{ Season } \\
\hline Rainy & 1 & & \\
\hline Less rainy & $0.881(0.451,1.719)$ & $0.138(1)$ & 0.710 \\
\hline Warm & $0.257(0.117,0.568)$ & $11.316(1)$ & 0.001 \\
\hline \multicolumn{4}{|l|}{ Gender } \\
\hline Female & 1 & & \\
\hline Male & $0.772(0.445,1.338)$ & $0.852(1)$ & 0.356 \\
\hline \multicolumn{4}{|l|}{ Admission } \\
\hline No & 1 & & \\
\hline Yes & $3.504(1.295,9.478)$ & $6.100(1)$ & 0.014 \\
\hline
\end{tabular}


Malaysian Journal of Public Health Medicine 2021, Vol. 21 (2): 315-320

Table 3: Final model of factors associated with HFMD outbreak cases in Kelantan in 2018 among children age less than 5 years $(n=146)$

\begin{tabular}{|c|c|c|c|c|}
\hline Variable & Adjusted $B$ & $\begin{array}{l}\text { Adjusted OR } \\
(95 \% \mathrm{Cl})\end{array}$ & Wald statistics (df) & $p$-value \\
\hline \multicolumn{5}{|l|}{ Institution } \\
\hline Nursery & & 1 & & \\
\hline Kindergarten & -1.110 & $0.330(0.114,0.957)$ & 4.163 & 0.041 \\
\hline Other* & -4.783 & $0.008(0.001,0.067)$ & 20.394 & $<0.001$ \\
\hline \multicolumn{5}{|l|}{ Season } \\
\hline Rainy & & 1 & & \\
\hline Less rainy & -0.228 & $0.796(0.255,2.489)$ & 0.153 & 0.695 \\
\hline Warm & -1.872 & $0.154(0.043,0.557)$ & 8.138 & 0.004 \\
\hline
\end{tabular}

* children who were taken care at home

When the multiple logistic regression was re-run for HFMD cases below 5 years old, the result of final model as shown in Table 3 showed that seasonal factor and institution had significant association with HFMD outbreak cases when other variables were controlled.

Children less than 5 years old who were from kindergarten had $67.0 \%$ lower odds of HFMD outbreaks compared to children from nursery when season was constant and other variables were controlled (Adj. OR 0.330; 95\% Cl: 0.114, 0.957 , $p$-value $=0.041$ ), while children less than 5 years old who were taken care by family members at home had $99.2 \%$ lower odds of HFMD outbreaks compared to those from nursery (Adj. OR 0.008; 95\% Cl: $0.001,0.067$, p-value<0.001) when the season was constant and other variables were controlled. The disease that occurred in the warm season among children aged less than 5 years old had $84.6 \%$ lower odds of HFMD outbreak cases compared to the disease occurred in rainy season (Adj. OR 0.154; 95\% Cl: 0.043, 0.557, pvalue $=0.004$ ) when the type of institution was constant and other variables were controlled.

\section{DISCUSSION}

Children less than five years of age were the most susceptible group of HFMD outbreaks in the northeastern state of Malaysia. The study showed that there was a significant association between HFMD outbreak cases with the institution type among the children under five years old. Their attendance to the kindergartens had lower odds $(0.330)$ compared to those who attended nurseries. Nursery is a highly prone place for an outbreak of HFMD compared to kindergarten because nursery cares for children aged three and below. Children aged between two and four years are more susceptible to infection due to the diminish of natural circulating antibodies to fight viruses. The level of antibodies that they received from their mothers from breastfeeding declined as they reach the age of 6 months ${ }^{3}$. Children under 5 years of age often unrealized that they suffer from HFMD, therefore, they are not telling the caregiver, and this may enhance the potential for HFMD transmission in the nursery setting. Our finding was similar with the results in Beijing, China, which established kindergarten attendance as a protective factor for HFMD outbreaks among children under 5 years of age ${ }^{18}$. Besides, one possible explanation is that children in the nursery spend around 8 hours a day as their parents are working. This raises the exposure period for HFMD as they communicate directly with each other while playing and sharing the same toys, using the same utensils, and washing and bathing in the same toilets throughout the period ${ }^{19}$.

Other than that, we also found that children less than 5 years old who were taken care by family members at home had lower odds (0.008) compared to those who attended nursery. Homecare in contrast to a daycare centre was shown to be a protective factor for severe HFMD, as described in a study in China ${ }^{20}$. The risk of HFMD infection could be minimized if children are cared for at home as it minimized direct interaction with other infected children. Another potential reason is that more children were sent than cared for at home, resulting in crowded nursery conditions as the crowded area can increase HFMD transmission, since they frequently had close interaction with one another.

The second significant finding in our study was the occurrence of the disease during warm season among children aged less than 5 years old had lower odds compared to the occurrence of the disease during the rainy season. This outcome was similar to the research conducted in Thailand in 2003 to 2012 by Samphutthanon, Tripathi ${ }^{12}$ and in 2016 by Upala, Apidechkul ${ }^{13}$. The potential explanation for rising outbreak cases during the rainy season is attributed to a shift in child behavior trend, since they are more likely to increase interaction with each other such as playing similar toys and other stuff in childcare facilities. Besides, the immune system of children under 5 years of age also often declined during 
the rainy season and thus resulted of virus transmission. However, the finding differed from the studies that had been conducted in China by Wang et $\mathrm{al}^{21}$ and in Singapore by $\mathrm{Hii}$ et $\mathrm{al}^{22}$ where a warm season may be favorable for the spread of the HFMD virus as it can be associated with behavioural trends which greatly increase children's engagement in public areas.

Based on data in 2018 through the HFMD surveillance system in Kelantan, the findings can assist in the evaluation of risk factors for HFMD outbreak cases in Kelantan. Ministry of Health, particularly Kelantan State Health Department is expected to gain benefit from this study and use it to formulate a suitable plan or update current HFMD prevention and control program guideline for the future use especially in the childcare centers context. However, there are several limitations that can be improvised for future research. This analysis was conducted in Kelantan State only. Therefore, our data might not represent all the HFMD cases in the country. Furthermore, since we used secondary data from CDCIS e-Notifikasi as sources for data collection, the completion of data in these systems was a major concern as many clinically relevant data remained incomplete even on verification. In addition, there were often minimal variables available in the secondary data resulting in a difficulty to determine the degree to which different influences such as the environment, culture or climate considered to be associated with the occurrence of an outbreak. Besides, these factors also can often differ based on geographical circumstances, such as the region or country, and temporal conditions.

Another approach for analysis in the outbreak study is to do cluster analysis through multilevel modelling. Clustering involves grouping of similar characteristics of a given set of elements. By analyzing the clusters, we can discover common or discriminative factors among the groups that are likely to affect disease occurrence patterns. In the study, even though we have 22 clusters of HFMD in Kelantan in 2018, we are unable to apply the cluster analysis because each cluster had less than 5 cases and this can cause it to be underpowered.

\section{CONCLUSION AND RECOMMENDATION}

In conclusion, among the children below than 5 years, type of institution such as kindergarten and homecare and season factor such as warm season were found to have a significant association to lower the risk for HFMD outbreak cases in the study. The collaboration among the authorities such as Community Welfare Department (JKM) and Ministry of Education (MOE) with the $\mathrm{MOH}$ is essential to continuously monitor and improvise the existing particular programs related to HFMD especially on the guideline for handling children in childcare centers and schools. These initiatives aim to improve knowledge, attitude and practice among institution administrators, teachers and staff towards HFMD.

Further research that encompasses of potential additional factors such as sign and symptom of HFMD, type of enterovirus detection, severity of cases, climate factors such as cumulative rainfall and temperature of the environment, knowledge, attitude and practice is recommended in order to reliably identify the associated factors that can be utilised to improve the current HFMD outbreak management. This kind of research can be conducted at the national level in the future study to evaluate the epidemiology of the HFMD outbreak in Malaysia thereby to improve the guideline on prevention and control guideline of HFMD outbreak.

\section{ACKNOWLEDGEMENTS}

The authors would like to thank the Director of Kelantan State Health Department and Communicable Disease Control Unit for providing the data on HFMD in Kelantan in 2018. Authors would like to thank all the participants especially to the Universiti Sains Malaysia, Kelantan on providing essential information.

\section{ETHIC APPROVAL}

Ethical approval was obtained from Jawatankuasa Etika Penyelidikan Manusia of Universiti Sains Malaysia (JEPeM Code: USM/JEPeM/19100597) and Medical Research and Ethics Committee (MREC), Ministry of Health (NMRR-19-3104-51280 (IIR)). Permission for data access was obtained from the Director of Kelantan State Health Department. Confidentiality was maintained throughout the study.

\section{Conflict of interest}

The authors declare no potential conflict of interest.

\section{REFERENCES}

1. Esposito S, Principi N. Hand, foot and mouth disease: current knowledge on clinical manifestations, epidemiology, aetiology and prevention. European journal of clinical microbiology \& infectious diseases : official publication of the European Society of Clinical Microbiology 2018; 37(3): 391-398.

2. Bian L, Wang Y, Yao X, Mao Q, Xu M, Liang Z. Coxsackievirus A6: a new emerging pathogen causing hand, foot and mouth disease outbreaks worldwide. Expert Review of Anti-infective Therapy 2015; 13(9): 1061-1071.

3. Gui J, Liu Z, Zhang T et al. Epidemiological Characteristics and Spatial-Temporal Clusters of Hand, Foot, and Mouth Disease 
in Zhejiang Province, China, 2008-2012. PLOS ONE 2015; 10(9): e0139109.

4. Chua KB, Kasri AR. Hand foot and mouth disease due to enterovirus 71 in Malaysia. Virologica Sinica. [journal article] 2011; 26(4): 221.

5. Chan Y-F, Sam I-C, Wee K-L, Abubakar S. Enterovirus 71 in Malaysia: A decade later. Neurology Asia 2011; 16(1): 1-15.

6. Chen $\mathrm{Y}$, Badaruddin $\mathrm{H}$, Lee VJ, Cutter J, Cook AR. The Effect of School Closure on Hand, Foot, and Mouth Disease Transmission in Singapore: A Modeling Approach. The American journal of tropical medicine and hygiene 2018; 99(6): 16251632.

7. Crabol Y, Pean P, Mey C et al. A prospective, comparative study of severe neurological and uncomplicated hand, foot and mouth forms of paediatric enterovirus 71 infections. International journal of infectious diseases : IJID : official publication of the International Society for Infectious Diseases 2017; 59: 69-76.

8. Inta C, Apidechkul T, Sittisarn S et al. Factors associated with hand foot mouth disease among children in day care center, Chiang Rai, Thailand. Asian Pacific J Trop Dis 2017; 7(7): 391-395.

9. Qiu J, Yan H, Cheng $\mathrm{N}$ et al. The Clinical and Epidemiological Study of Children with Hand, Foot, and Mouth Disease in Hunan, China from 2013 to 2017. Sci Rep 2019; 9(1): 11662.

10. Mao L-X, Wu B, Bao W-X et al. Epidemiology of hand, foot, and mouth disease and genotype characterization of Enterovirus 71 in Jiangsu, China. Journal of Clinical Virology 2010; 49(2): 100-104.

11. Li J, Zhu R, Huo D et al. An outbreak of Coxsackievirus A6-associated hand, foot, and mouth disease in a kindergarten in Beijing in 2015. BMC pediatrics 2018; 18(1): 277.

12. Samphutthanon R, Tripathi NK, Ninsawat S, Duboz R. Spatio-temporal distribution and hotspots of Hand, Foot and Mouth Disease (HFMD) in northern Thailand. Int $J$ Environ Res Public Health 2013; 11(1): 312-336.

13. Upala P, Apidechkul T, Suttana W, Kullawong N, Tamornpark R, Inta C.
Molecular epidemiology and clinical features of hand, foot and mouth disease in northern Thailand in 2016: a prospective cohort study. BMC Infect Dis 2018; 18(1): 630-630.

14. Communicable Disease Unit. HFMD Statistics of Kelantan 2018. Kota Bharu,: Kelantan Health Department 2019.

15. Kelantan Health Department. Kelantan Weekly Epid Review. Kota Bharu: Kelantan State Health Department 2019. 23-29 Disember 2018.

16. Suhaila J, Deni SM, Zin WZW, Jemain AA. Trends in Peninsular Malaysia Rainfall Data During the Southwest Monsoon and Northeast Monsoon Seasons: 1975-2004. Sains Malaysiana 2010; 39(4): 533-542.

17. $\mathrm{MOH}$ Malaysia. Case Definitions for Infectious Diseases In Malaysia. Putrajaya, Malaysia: MOH Malaysia 2017.

18. Xiaona W, Ying S, Changying L et al. A CaseControl Study to Identify Environmental Risk Factors for Hand, Foot, and Mouth Disease Outbreaks in Beijing. Jpn J Infect Dis 2014; 67(2): 95-99.

19. Mahadzar SAS, Abdul Rahman $H$. Knowledge, Attitude and Practice towards Hand, Foot and Mouth Disease (HFMD) Among Nursery Governesses in Klang Valley, Selangor. Malaysian J Med Health Sci 2019; 15(SP4): 40-47.

20. Zeng M, Pu D, Mo X et al. Children of ruralto-urban migrant workers in China are at a higher risk of contracting severe hand, foot and mouth disease and EV71 infection: a hospital-based study. Emerging Microbes \& Infections 2013; 2(1): 1-6.

21. Wang XF, Lu J, Liu XX, Dai T. Epidemiological Features of Hand, Foot and Mouth Disease Outbreaks among Chinese Preschool Children: A Meta-analysis. Iranian journal of public health 2018; 47(9): 1234-1243.

22. Hii YL, Rocklöv J, Ng N. Short Term Effects of Weather on Hand, Foot and Mouth Disease. PLOS ONE 2011; 6(2): e16796. 